\title{
A novel plant growth simulation algorithm and its application
}

\author{
Fang Liu ${ }^{1, \mathrm{a}}$ Yueguang $\mathrm{Li}^{2, \mathrm{~b}}$ \\ ${ }^{1}$ Gansu Normal University for Nationalities, Hezuo, gansu, 747000, \\ China \\ ${ }^{2}$ Gansu Normal University for Nationalities, Hezuo, gansu, 747000, \\ China \\ ${ }^{a}$ Yueguangli7@163.com, ${ }^{b}$ Yueguangli7@sohu.com
}

\begin{abstract}
:
At present, much of the city is construct the new public traffic line, meet the needs of the development of city. Firstly, this paper describes the influence factors of conventional bus station location problem, and then gives the mathematical model of bus station location problem, and put forward to the algorithm of solving the problem of, and finally validated by examples.
\end{abstract}

Keywords: Plant growth simulation algorithm; the site of the urban public transport station; Influence factors; mathematical model

\section{Introduction}

The bus station is the important part of city infrastructure, bus station layout not only affects the advantages and disadvantages of the set of bus lines, but also it is related to the interests of bus companies and travelers. Although the bus station is only a node of on the bus lines, but it not only affects the running speed and the stop frequency of the public transit vehicle in the sections, but also decides the efficiency of passenger travel. If the bus line station and the distance between stations is larger, it can not meet the growing passenger travel demand; instead, it will reduce the public transit vehicle running speed and road capacity, at the same time it will cause the infrastructure of repeated construction and waste of resources, it is not conducive to raise the level of city public transportation and city economic development. Therefore, it is very important to determine the location of the site and the number of the bus lines, it is not only 
related to the quality and the efficiency of public transport, but also it affects road traffic transportation quality and city environment ${ }^{[1-4]}$.

\section{Mathematical model of the urban public transport station problem}

According to the city public transportation site location factors, the establishment of specific mathematical model, the models are as follows:

$$
\text { Min : } T_{v}=T_{c}+T_{b}+T_{s}=\frac{L}{V}+t_{d} * z+\frac{2 p h}{u}
$$

s.t

$$
N=\frac{2\left(T_{v}+T_{t}\right)}{h}=\frac{2\left(\frac{L}{v}+t_{d} * z+2 p h / \mu+T_{t}\right)}{h}
$$

Constraint condition:

$$
\begin{aligned}
& y=\text { random }(-0.5,0.5) \\
& \frac{d}{4} \leq y * L_{1} \\
& M \leq M C_{C} \\
& d \geq L_{m}
\end{aligned}
$$

Among them: $T_{v}$ expresses Vehicles running time at the start and the end; $T_{c}$ expresses vehicles running time at a steady speed $\mathrm{V} ; T_{b}$ expresses vehicles lost time due to stop; $T_{s}$ expresses passengers get on and off time when vehicles stop; $t_{d}$ expresses vehicles loss time at a deceleration or an acceleration; $\mathrm{Z}$ expresses the station number; $\mu$ expresses getting on or 
alighting number in the unit of time; ${ }^{L}$ expresses bus line length; P passenger demand in per unit length of bus line; $h$ expresses the bus average departure interval time; $T_{t}$ expresses end turnaround time; $\mathrm{N}$ expresses system configuration the number of vehicles; D expresses the average station spacing; L1 expresses passengers tolerance maximum walking distance; $M$ expresses departure frequency; Mc expresses allow of departure frequency; Lm represents the minimum design distance between stations .

\section{The plant growth simulation algorithm}

Plant growth simulation algorithm (PGSA) is an evolutionary computation technique through simulating the growth processes in plants, which is based on the principles of plant phototropism growth ${ }^{[5]}$. The algorithm has a good prospect in the application due to requiring a simple on the parameters. It has gradually been applied in the field of engineering by many scholars ${ }^{[6]}$. PGSA sets up several basic conception: root trunk 、 branch、 growth point and light source. The root of a plant expresses initial solution; the trunk and branch correspond to the search domain of possible solutions; the selected growth point expresses the base of next searching process and the light source represents the global optimal solution. The key point of PGSA is selecting one growth point to erupt into branch, and ensuring the branch growing toward the light source.

Plants can be viewed as a system, which composes of a large number of branches and nodes. It must be as soon as possible to strive for breeding more branches and leaves for earning more surface areas, which can obtain the greatest possible sunlight. The form of grammar that simulates the plant description analysis and development had been established since linguistics was introduced into the biological, which based on a simple rewrite rules and branching rules, this is called L-system. Formal description of plant growth can be carried out as the following: 
1. The section of the site grow new branches which first emerged in a number of stems is called the growth node.

2. Most of the new branches have grown updated branches, and the process repeated on the old and new branches.

3. Different branches in the tree have similarities with each other, and the entire plant has self-similar structure.

The Branching model of plant growth is improved according to L-system combined with computer graphics and fractal theory, the plant, as the form of plant growth characteristics, can be described as follow: Supposed branches of plant growth occurred in the two-dimensional plane, Each branch growing in units length every time, or rotating a certain angle $\alpha$, Starting from the node of trunk or branches, The growth process were repeated through rewriting the rules of branches of plant growth in the two dimensional plane.

It was proved by biological experiments that a new branch that is able to grow depends on its morphactin concentration when the plant has more than one node. The node which has larger value of morpheme concentration has more growth opportunities than the smaller one, morphactin concentration are not pre-assigned to the nodes, but formed according to their location information which we call that plant showed the feature of plant's Phototropism. After the node has been formed, morphactin concentration will be readjusted according to changing in the environment of a new growth node else.

We could describe the characteristics of plant growth in term of the mathematical view basis on plant growth analysis of the above. Suppose the length of tree trunk is $\mathrm{T}$, the length of branch is $\mathrm{L}$, there are $\mathrm{W}$ growing nodes $S_{T}=\left(S_{T 1}, S_{T 2}, \ldots, S_{T W}\right)$ in the trunk, morphactin concentration of those nodes is $P_{T}=\left(P_{T 1}, P_{T 2}, \ldots, P_{T W}\right) \quad$ respectively. There are $q$ growth nodes $S_{T}=\left(S_{T 1}, S_{T 2}, \ldots, S_{T q}\right)$ in the branch. Morphactin concentration of those nodes is $P_{T}=\left(P_{T 1}, P_{T 2}, \ldots, P q\right)$ respectively. The morphactin concentration which grown in the trunk and branch is calculated as follows: 


$$
P_{T i}=f\left(x_{0}\right)-f\left(S_{T i}\right) / \sum_{i}^{W}\left(f\left(x_{0}\right)-f\left(S_{T i}\right)\right)+\sum_{j}^{q}\left(f\left(x_{0}\right)-f\left(x_{T q}\right)\right)
$$

Where $x_{0}$ represents the root of plant (the initial node), $f(*)$ is the information function of the node in the environment, The smaller value of the function as possible shows the better environment where the node located, it will help to grow new branch.

From formula (7), the value of morphactin concentration in every node depends on relative position of the relative to the initial root and the location of the environmental information, the mechanism consistent with the formation of the morphactin concentration in the plant cell. We can deduced from formula (7) as follows:

$$
\sum_{i=1}^{T} \sum_{j=1}^{q}\left(P_{T i}+P_{T j}\right)=1
$$

We can produce random number in the interval $[0,1]$. The random number must fall within one of the state space $\left(P_{1}, P_{2}, \ldots, P_{T+q}\right)$, where the corresponding node will have a prior right to grow new branch. A simple example of morphactin concentration state space displays in the fig. 1.The value of morphactin concentration in all nodes will change after the new branch has grown up. Computation formula of the value of morphactin concentration in other nodes will add the relevant node on the new branch, and remove the grown node, which basis on formula (7). The process will be repeated until there is no new branches growing.

\section{The analysis of simulation}

The paper selects a bus line of Lanzhou city. Combined with the data of the bus line, the model is applied to solve optimal stop spacing and number of sites. 
The results are shown in Table 1 and Table 2. We can see that score of each site are more than 80 points, it is quite consistent with the evaluation standard of site selection. The average score of these sites is 83.6, indicating that the site layout is reasonable.

Table1 Evaluation standard

\begin{tabular}{|c|c|c|c|c|c|}
\hline & {$[90-100]$} & {$[80-90]$} & {$[70-80]$} & {$[60-70]$} & {$[0-60]$} \\
\hline Index 1 & 300,400 & 400,500 & 500,600 & 600,700 & $\begin{array}{c}>700 \text { or } \\
<300\end{array}$ \\
\hline Index 2 & $>0.8$ & $0.8-0.7$ & $0.7-0.6$ & $0.6-0.5$ & $<0.5$ \\
\hline Index 3 & $0-200$ & $200-300$ & $300-400$ & $400-500$ & $>500$ \\
\hline Index 4 & $>1000$ & $800-1000$ & $600-800$ & $400-600$ & $<400$ \\
\hline Index 5 & $\mathrm{A}$ & $\mathrm{A}$ & $\mathrm{B}$ & $\mathrm{B}$ & $\mathrm{C}$ \\
\hline Index 6 & $<3$ & $3-4$ & $4-5$ & $5-6$ & $>6$ \\
\hline Index 7 & $0.4-1$ & $0.3-0.4$ & $0.2-0.3$ & $0.1-0.2$ & $0-0.1$ \\
\hline Index 8 & $0-200$ & $200-300$ & $300-400$ & $400-500$ & $>500$ \\
\hline
\end{tabular}

Table2 Evaluation value of sites

\begin{tabular}{|c|c|c|c|c|c|c|c|c|c|}
\hline $\begin{array}{c}\text { Site } \\
\text { number }\end{array}$ & $\begin{array}{c}\text { Index } \\
1\end{array}$ & $\begin{array}{c}\text { Index } \\
2\end{array}$ & $\begin{array}{c}\text { Index } \\
\text { Index }\end{array}$ & $\begin{array}{c}\text { Index } \\
5\end{array}$ & $\begin{array}{c}\text { Index } \\
6\end{array}$ & $\begin{array}{c}\text { Index } \\
7\end{array}$ & $\begin{array}{c}\text { Index } \\
8\end{array}$ & Score \\
\hline 1 & 18.42 & 6.27 & 41.58 & 10.17 & 9.18 & 23.56 & 21.07 & 30.27 & 80.3 \\
\hline 2 & 17.35 & 5.35 & 44.06 & 11.71 & 12.24 & 20.94 & 22.10 & 34.14 & 83.9 \\
\hline 3 & 17.35 & 5.52 & 47.03 & 13.25 & 12.24 & 18.56 & 22.36 & 34.50 & 85.4 \\
\hline 4 & 22.69 & 5.77 & 47.52 & 10.01 & 12.24 & 20.47 & 20.82 & 30.98 & 85.2 \\
\hline 5 & 26.42 & 5.44 & 49.01 & 9.24 & 14.54 & 14.28 & 21.33 & 31.33 & 85.8 \\
\hline 6 & 26.42 & 6.69 & 42.57 & 9.24 & 14.54 & 22.85 & 20.05 & 26.05 & 84.2 \\
\hline 7 & 20.29 & 5.02 & 48.02 & 13.56 & 13.77 & 14.28 & 21.85 & 30.98 & 83.9 \\
\hline 8 & 20.29 & 6.44 & 42.57 & 9.24 & 14.54 & 22.37 & 21.59 & 31.33 & 84.2 \\
\hline 9 & 21.09 & 6.19 & 46.53 & 12.02 & 9.18 & 18.56 & 22.62 & 33.79 & 85.0 \\
\hline 10 & 20.55 & 6.10 & 42.57 & 12.17 & 9.18 & 19.99 & 20.30 & 29.22 & 80.0 \\
\hline
\end{tabular}




\section{Conclusions}

In this paper, for the site location problem, this paper gives an example of calculation and analysis, evaluate the location plan. Experiments show that this method is practical, simple and easy to understand.

\section{References}

[1] Wang Lin, Chen Dapeng. Analysis and Fuzzily Appraisement of the Choice for the Site of the Public Transport. Technology \& Economy in Area of Communications. 2009(1):43-45.

[2] Zeng Hui. Android system architecture and security mechanisms[J].Information system Engineering. 2012 (01):123-130.

[3] Lin, J.-R., Nozick, L. K., \& Tumquist, M. A. (2006). Strategic design of distribution systems with economies of scale in transportation. Annals of Operations Research, 144(1),161-180.

[4] David K. George, Cathy H. Xia, Fleet-sizing and service availability for a vehicle rental system via closed queuing networks. European Journal of Operational Research 211 (2011) 198-207.

[5] Li T, Wang C F, et al. A global optimization bionics algorithm for solving integer Programming plant growth simulation algorithm[J] .Systems Engineering - Theory \& Practice ,2005,25(1) :76 - 85.

[6] Li T, Wang Z t. Application of plant growth simulation algorithm on solving facility location problem [J]. Systems Engineering - Theory \& Practice, 2008, (12):107-115 